\title{
Static and dynamic characteristics of proportional directional valve
}

\author{
Marian Ledvoň ${ }^{1 *}$, Lumír Hružík ${ }^{1}$, Adam Bureček $^{1}$ and Martin Vašina ${ }^{1}$ \\ ${ }^{1}$ VŠB-Technical University of Ostrava, Faculty of Mechanical Engineering, Department of Hydromechanics and Hydraulic Equipment, \\ 70833 Ostrava, Czech Republic
}

\begin{abstract}
This article deals with experimental measurement and numerical simulation of static and dynamic characteristics of the proportional directional valve. The characteristics of the proportional directional valve are measured on experimental equipment. At the static characteristic, pressure drop on the proportional directional valve, flow and oil temperature are measured on this equipment. The spool position is measured to determine of the dynamic characteristic of the proportional directional valve. Mathematical model of the proportional directional valve is created using Matlab SimScape Fluids software and is complemented by a mathematical model of the experimental equipment. The simulation results on the mathematical model are compared with the results of the experimental measurement.
\end{abstract}

\section{Introduction}

Proportional directional valves are widely used in industrial applications. They are mainly characterized by the possibility of continuous direction and flow rate control. A low power control is used in proportional directional valve control. This signal can be easily programmed. The proportional directional valve properties can be described by characteristics [1]. Dynamic characteristics describe the ability of the proportional directional valve to respond to rapid changes of the control signal. Static characteristics describe the properties of the proportional directional valve in a steady state. Simulation of hydraulic systems operating conditions with proportional directional valve is possible by computer technology. A verification of different initial conditions is the main advantage of the simulation. System deficiencies can be identified before its realization. It is also possible to solve problems with the hydraulic system in operation. Mathematical model to simulate the proportional directional valve was designed using Matlab Simulink. The proportional directional valve model was assembled from blocks that are described by mathematical equations. Individual blocks are included in the SimScape Fluids library. The proportional directional valve model includes the influence of inertial forces, viscous friction and stiffness of the spring acting on the spool.

\section{Description of experimental equipment}

The experimental hydraulic circuit was built according to the scheme (see Figure 2). The basic part of the hydraulic circuit is the hydraulic aggregate HA. The tested element is the proportional directional valve PDV from Argo Hytos, designated PRL2-06-32-0-24. The hydraulic aggregate consists of the hydraulic pump with fixed displacement HP, which is drive by the electric motor EM, the relief valve RV, the check valve $\mathrm{CV}$ and the return filter RF. The hydraulic pump starts delivering the working fluid from the tank $\mathrm{T}$ to the circuit after starting the hydraulic aggregate. The required pressure in the circuit is set on the relief valve. The check valve serves as a protection of the hydraulic pump against return shocks. The working fluid is filtered through a pressure filter PF. This filter is in front of the proportional directional valve PDV to maintain the required purity of the working fluid. Behind the proportional directional valve is the pipe $\mathrm{P}$. The change of flow in the circuit is realized by means of the throttle valve TV. There are connected pressure sensors $S_{1}$ and $\mathrm{S}_{2}$, before and behind the proportional directional valve, the flowmeter $S_{3}$ and the temperature sensor $S_{4}$ (see Figure 1) in the circuit. The working fluid is oil with the kinematic viscosity $v=40.8 \mathrm{~mm}^{2} \cdot \mathrm{s}^{-1}$ at the oil temperature $t_{\mathrm{O}}=40^{\circ} \mathrm{C}$.

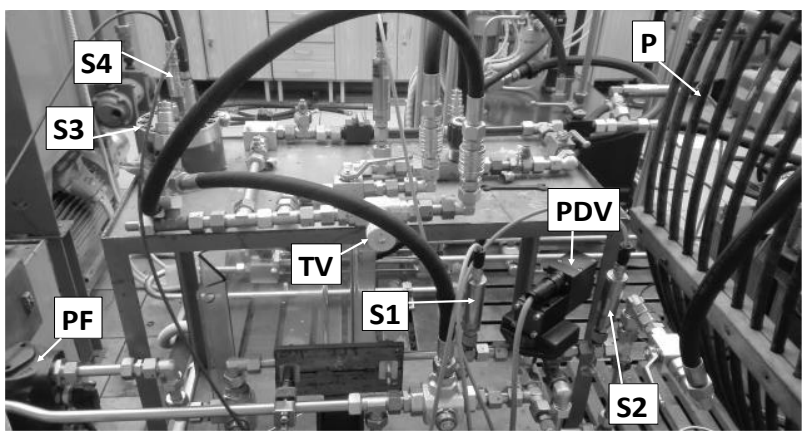

Fig. 1. Experimental equipment

*Corresponding author: marian.ledvon @ vsb.cz 


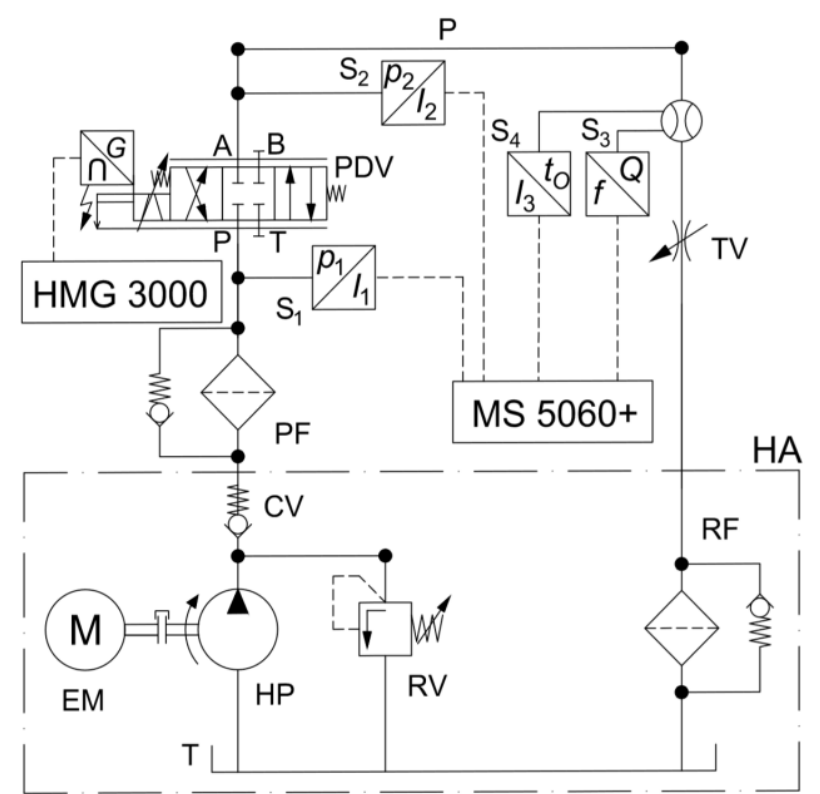

Fig. 2. Scheme of hydraulic circuit of experimental equipment

Table 1. List of used parts

\begin{tabular}{|c|c|}
\hline EM & Electric motor \\
\hline HP & Hydraulic pump \\
\hline RV & Relief valve \\
\hline RF & Return filter \\
\hline PF & Pressure filter \\
\hline PDV & Proportional directional valve \\
\hline TV & Throttle valve \\
\hline P & Pipe \\
\hline HA & Hydraulic aggregate \\
\hline T & Tank \\
\hline CV & Check valve \\
\hline$S_{1}$ & Pressure sensor PR15 \\
\hline$S_{2}$ & Pressure sensor PR15 \\
\hline$S_{3}$ & Flowmeter QG100 \\
\hline$S_{4}$ & Temperature sensor PT100 \\
\hline
\end{tabular}

\section{Measurement of proportional directional valve characteristics}

\subsection{Static $\Delta p-Q$ characteristic}

The static $\Delta p-Q$ characteristic was measured in the P-A valve channel. The pressure $p_{1}$ in channel $\mathrm{P}$ and the pressure $p_{2}$ in channel A of the proportional directional valve, the flow $Q$ in front of the throttle valve and the working fluid temperature $t_{\mathrm{O}}$ were measured for the determination of the characteristics. The measurement was made as follows: The pressure on the relief valve is set on the value $p_{R V}=100 \mathrm{bar}$. The control signal of the proportional directional valve is generated on the computer in the Matlab Simulink. The flow rate is gradually reduced using the throttle valve TV until the valve is fully closed. The pressure drop $\Delta p$ on the proportional directional valve PDV will change with every change of flow rate $Q$. The values of the measured quantities are subtracted from the measuring device display after they have been stabilized. This measurement is repeated for the input control signal of the proportional directional valve in the voltage range $U=(0.5 \div 10) \mathrm{V}$. The MS5060 + measuring device and sensors from Hydrotechnik were used in measurement.

\subsection{Transient characteristic}

The transient characteristic shows the time dependence of the proportional directional valve spool position for the step input control signal. The transient characteristic was measured at zero flow through the proportional directional valve. The step control signal of the proportional directional valve is generated on the computer using Matlab Simulink. The transient characteristic was measured for the step change $25 \%$, $50 \%, 75 \%$ and $100 \%$ of the voltage $U$ from the maximum control voltage. The spool position was recorded by the measuring device Hydac HMG 3000. The measurement was recorded with the scanning rate of $0.1 \mathrm{~ms}$. The HMGWIN software was used to evaluate measurements.

\section{Measurement of spool stroke}

The dependence of the spool stroke on the input control voltage was measured for the correct setting of the proportional directional valve mathematical model (see Figure 3). The dependence of the spool stroke $s$ on the input control signal $U$ is linear.

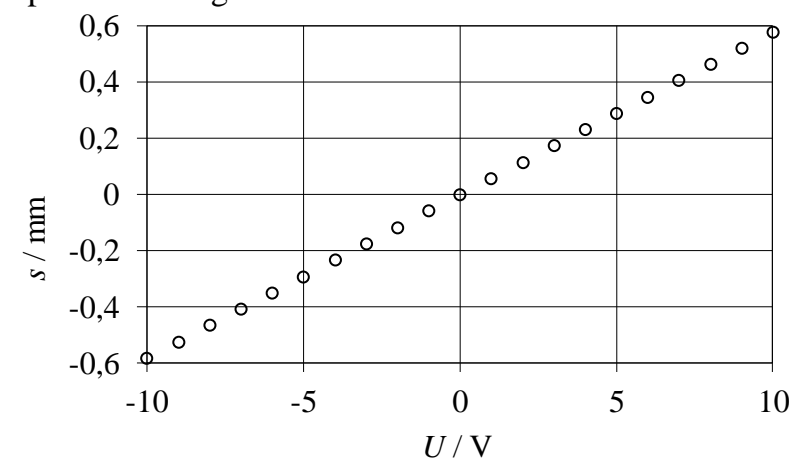

Fig. 3. Dependence of spool stroke $s$ on input voltage $U$

\section{Motion equation}

Dynamic properties of the hydraulic system can be simulated using mathematical models and computer technology. The axial forces are acting on the spool of the proportional directional valve (see Figure 4).

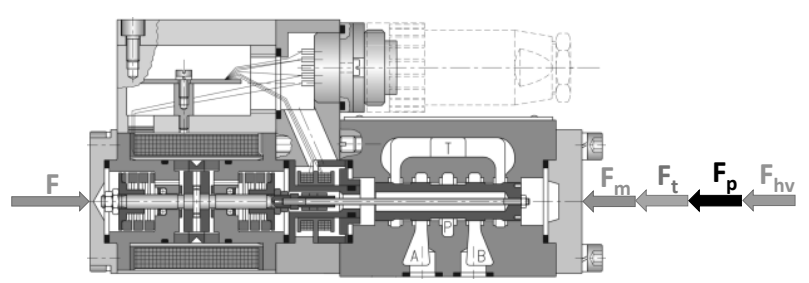

Fig. 4. Axial forces acting on the proportional directional valve spool [2]

A part of the proportional directional valve mathematical model can be described by the motion equation:

$$
F_{m}+F_{t}+F_{p}+F_{h v}=F
$$

where $F_{h v}$ is the spool valve flow force, $F_{m}$ is the inertial force, $F_{t}$ is the frictional force, $F_{p}$ is the spring force, $F$ is 
the solenoid force required for the proportional directional valve spool displacement.

\subsection{Spring force}

The spring force as well as the magnetic force is not constant. The spring force is changing depending on the spring compression, therefore it is proportional to the spool displacement and is given by:

$$
F_{p}=k \cdot\left(x_{0}+x\right)
$$

where $k$ is the spring stiffness, $x$ is the proportional directional valve spool displacement, and $x_{0}$ is the spring initial compression at the zero spool displacement.

\subsection{Friction force}

The force required to overcome friction is expressed as a function of the velocity and is given by:

$$
F_{t}=c \cdot \dot{x}
$$

where $c$ is the damping coefficient (viscous and Coulomb friction) and $\dot{x}$ is the first derivative of the spool displacement (velocity).

Friction loads include static friction, viscous friction and dry friction. Viscous and Coulomb friction predominates in many applications. Coulomb friction occurs between dry surfaces. This type of friction is proportional to the load but is independent on the speed. Viscous friction is proportional to the velocity between the two surfaces that are separated by the viscous film, but is independent of the load [3].

\subsection{Inertia force}

The inertia force corresponds to the spool mass and its value is proportional to the acceleration value according to the formula:

$$
F_{m}=m \cdot \ddot{x},
$$

where $m$ is spool mass including all connected parts and $\ddot{x}$ is second derivative of the spool displacement.

The flow force $F_{h v}$ does not act on the spool, because the transient characteristics were measured without flow.

\section{Mathematical model of experimental equipment}

The mathematical model of the proportional directional valve was created using Matlab SimScape Fluids [4]. The proportional directional valve mathematical model was complemented by the experimental circuit mathematical model (see Figure 5).

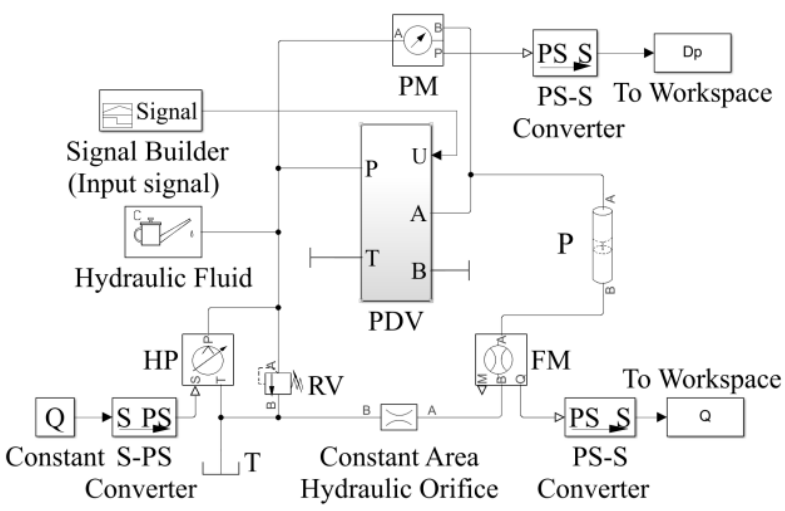

Fig. 5. Mathematical model of experimental equipment
The proportional directional valve PDV is listed as a subsystem PDV for better orientation and clarity of the model (see Figure 6). The hydraulic pump HP is a flow source in the hydraulic circuit. The pressure in the hydraulic circuit is set using the relief valve RV. The fluid flows through the proportional directional valve PDV into the pipe $\mathrm{P}$ and then back into the tank $\mathrm{T}$. The Hydraulic Fluid is used to adjust the physical properties of the oil. The input control voltage signal is generated by the Signal Builder. The model is further comprised of the pressure drop PM and the flow FM measurement block. By means the To Workspace, the values of the scanned quantities are recorded for a post-processing.

The proportional directional valve subsystem is created by individual flow channels of the proportional directional valve. Individual flow channels are created by the Orifice with Variable Rectangular Area Slot PA, PB, AT, BT (see Figure 6). The friction, spring, fixed stop and mass of the slide are included in the subsystem. The Spring represents the spring that acts on the spool and the spring stiffness is set here. A mechanical translation hard stop is set by the Hard Stop, which limits the spool stroke. The upper and lower stroke limits are set here. The Mass represents the mass of the proportional directional valve spool including all connected parts. The Friction includes the influence of viscous and Coulomb friction in the model. The Inerter is also included in the subsystem [5]. The spool position is measured by the Motion Sensor. The control voltage signal $U$ is at input to the subsystem PDV. It is firstly converted by the $U / s$ to the spool position $s$. The dependence of the spool position $s$ on the voltage $U$ is linear (see Figure 3). The feedback of the spool position $s$ and PID Controller are also included in the mathematical model. Subsequently, the spool position $s$ is converted by the $s / F$ to the electromagnetic transducer force $F$. The time dependence of the spool position $s$ is recorded using To Workspace (position).

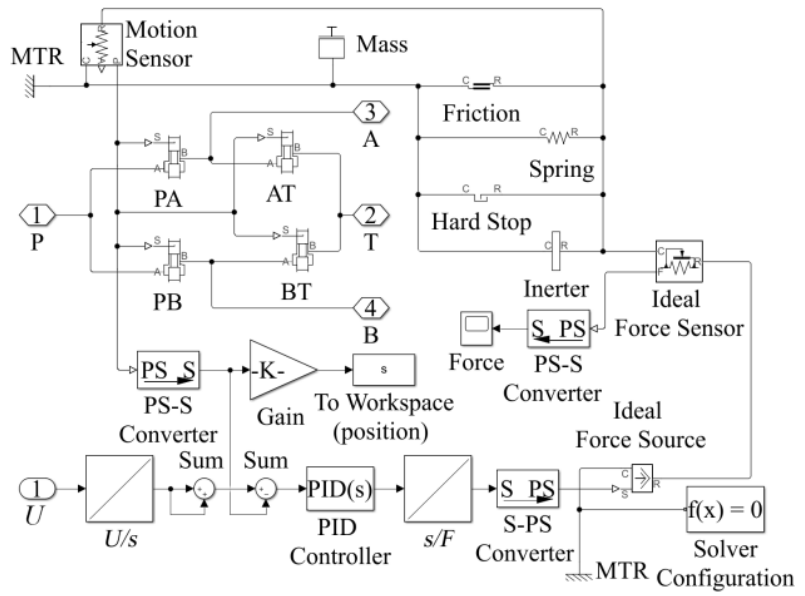

Fig. 6. Subsystem of proportional directional valve

\section{Comparison of experimental measurement and mathematical model}

The static $\Delta p-Q$ characteristics of the proportional directional valve determined by measurements and numerical simulations are compared in Figure 7. 


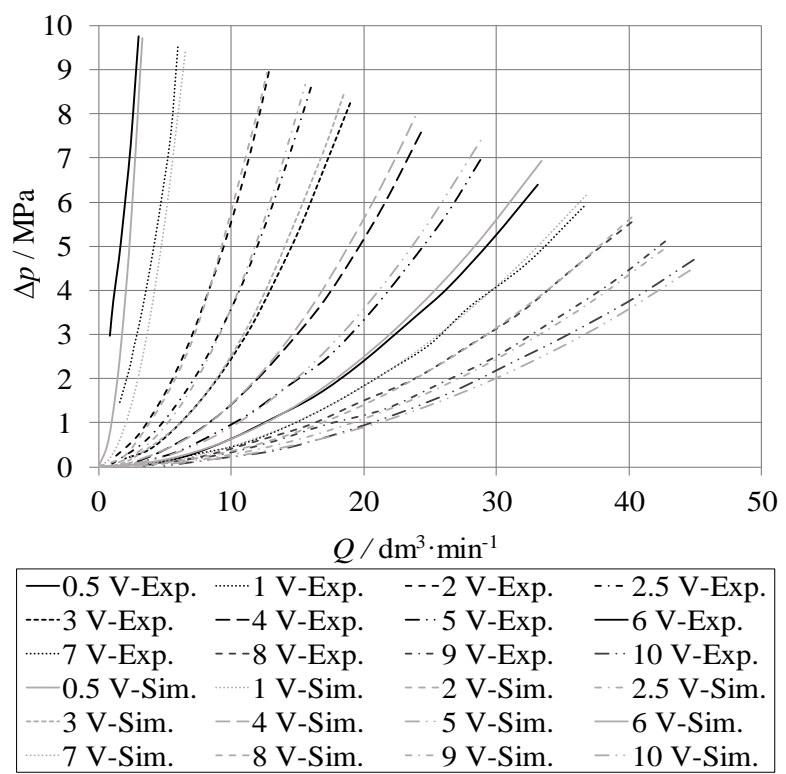

Fig. 7. Comparison of static $\Delta p-Q$ characteristics

For individual characteristics, the pressure drop $\Delta p$ increases with the increasing flow $Q$. Furthermore, at the same pressure drop $\Delta p$ the flow $Q$ increases with the increasing control voltage $U$. By comparing the measurements and the simulations, it can be seen that the mathematical model (Sim.) corresponds to experimental measurement (Exp.).

The transient characteristics for the individual input step signals determined by measurement and simulation are compared in the Figure 8 . For the 25\% step signal, the measured and simulated characteristics are identical and there is no overshoot above the desired value. For the characteristics with step signal $50 \%$ and $75 \%$, there is a small overshoot and then stabilization to the desired value. The mathematically simulated time dependencies of the spool positions $s$ correspond to the experiment. The measured transient characteristic for the $100 \%$ step signal generates a significant overshoot above the desired value. The simulated characteristic for the $100 \%$ step signal approximately corresponds to the measured characteristic. The overshoot at the simulated characteristic is not so significant.

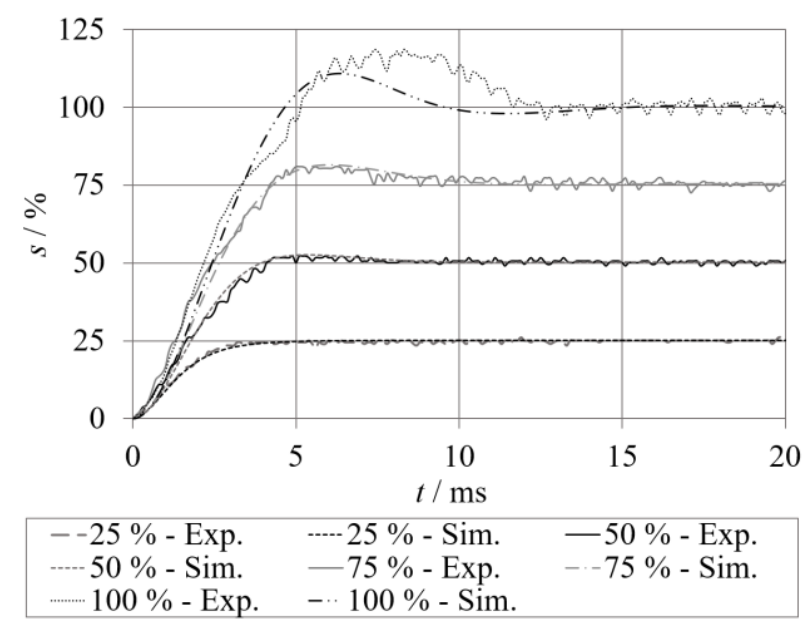

Fig. 8. Comparison of transient characteristics

\section{Conclusions}

This paper deals with the measurement and numerical simulation of the static and dynamic characteristics of the proportional directional valve. Firstly, a hydraulic circuit including all sensors to measure characteristics was designed. The proportional directional valve mathematical model, complemented by the hydraulic circuit mathematical model, was assembled in Matlab SimScape Fluids. To determine the correct settings of the proportional directional valve model, the proportional directional valve spool displacement depending on the input voltage was measured. When comparing the measured and simulated $\Delta p-Q$ characteristics, the mathematical model corresponds to the experiment. When comparing the measured and simulated transient characteristics, the mathematical model corresponds to the experiment.

This work was supported by the European Regional Development Fund in the Research Centre of Advanced Mechatronic Systems project, project number CZ.02.1.01/0.0/0.0/16_019/0000867 within the Operational Programme Research, Development and Education.

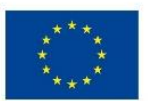

EUROPEAN UNION

European Structural and Investment Funds Operational Programme Research Development and Education

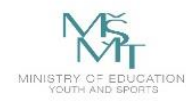

The work presented in this paper was supported by a grant SGS „Modeling and Experimental Verification of Dynamic Phenomena in Fluid and Vacuum Systems" SP2018/157.

\section{References}

1. Raduenz, H., Mendoza, Y.E.A., Ferronatto, D., Online fault detection system for proportional hydrau lic valves, J Braz. Soc. Mech. Sci. Eng., 40, 331, (2018)

2. Argo-Hytos, Company documentation, http://docplayer.cz/12388388-Prl2-popis-konstrukcea-funkce-hc-5103-12-98-s-linearnim-motorem-dn06-pmax-25-mpa-qmax-32-dm-3-min-1-nahrazujehc-5103-6-98.html

3. The MathWorks, Matlab Simulink User's Guide, SimHydraulics User's Guide (USA, 2007) https://www.mathworks.com/help/physmod/simscape /ref/translationalfriction.html?searchHighlight=frictio $\underline{\text { n\&s tid=doc srchtitle }}$

4. A. Bureček, L. Hružík, M. Vašina, EPJ Web of Conferences, EFM15, Simulation of dynamics of hydraulic system with proportional control valve, 114, 02008, (2016)

5. Shi, Xiang; Zhu, Songye, Dynamic characteristics of stay cables with inerter dampers, JOURNAL OF SOUND AND VIBRATION, 423, 287-305, (2018) https://doi.org/10.1007/s40430-018-1240-3 